\title{
Polling a Third Party Challenger: Fact or Artifact?
}

Peter J Woolley, Dan Cassino

Tags: survey practice

\section{Survey Practice}

Vol. 3, Issue 4, 2010

Polling a Third Party Challenger: Fact or Artifact?

Giving equal place to a third party or independent challenger may over-estimate his or her support by putting that candidate on an equal footing with much better known major party nominees. On the other hand, not reading the name of what might be a significant third party challenger may unfairly prejudice respondents in favor of the major party candidates and underestimate the third party challenger. We employed several methods to measure New Jersey voters' preferences in New Jersey's 2009 gubernatorial election, in which an independent challenger qualified for public campaign funds. While conventional wisdom suggested that the challenger's popularity quickly grew to as much as 20 percent before fading, evidence suggests otherwise: that the apparent popularity of the third party challenger was no more than an artifact of question construction.

When Christopher Daggett raised enough campaign money in his bid for the governor's office to qualify for public matching funds from the state of New Jersey, it was unusual, but it was an unusual year all around. The Democratic incumbent, John Corzine, was unpopular, dragged down by frustration with the economy, property taxes, and massive structural deficits. His Republican challenger, Chris Christie, was a Bush Administration appointee who admitted having received his post because of his success as a fundraiser for Bush in 2000, in a state where Bush concluded his presidency with an approval rating of just $21 \%{ }^{1}$

Obvious flaws in the two major party candidates led observers to expect a strong third party run, and Daggett, former Commissioner of the Department of Environmental Protection was off to a good start. He had raised more than the $\$ 340,000$ necessary to qualify for a 2 -to- 1 match from the state and would be included in the official debates. According to the largest statewide newspaper, which would eventually endorse Daggett, and the leader of an environment interest group, Daggett had gone "from a fringe candidate to somebody who has to be taken seriously." ${ }^{2}$ All this despite that in July, when

\footnotetext{
1 See Fairleigh Dickinson University's PublicMind, "New Day Dawning: Strong Approval for President-Elect; Bush Retrospective shows Long, Steep Decline,” Jan. 15, 2009 found at http://publicmind.fdu.edu/legacy/tab.html.
} 
the announcement was made, $89 \%$ of voters had not heard of him and $9 \%$ said they had heard of him but had no opinion of him. ${ }^{3}$

\section{Estimated \% Daggett Vote Share with Linear Trend Line}

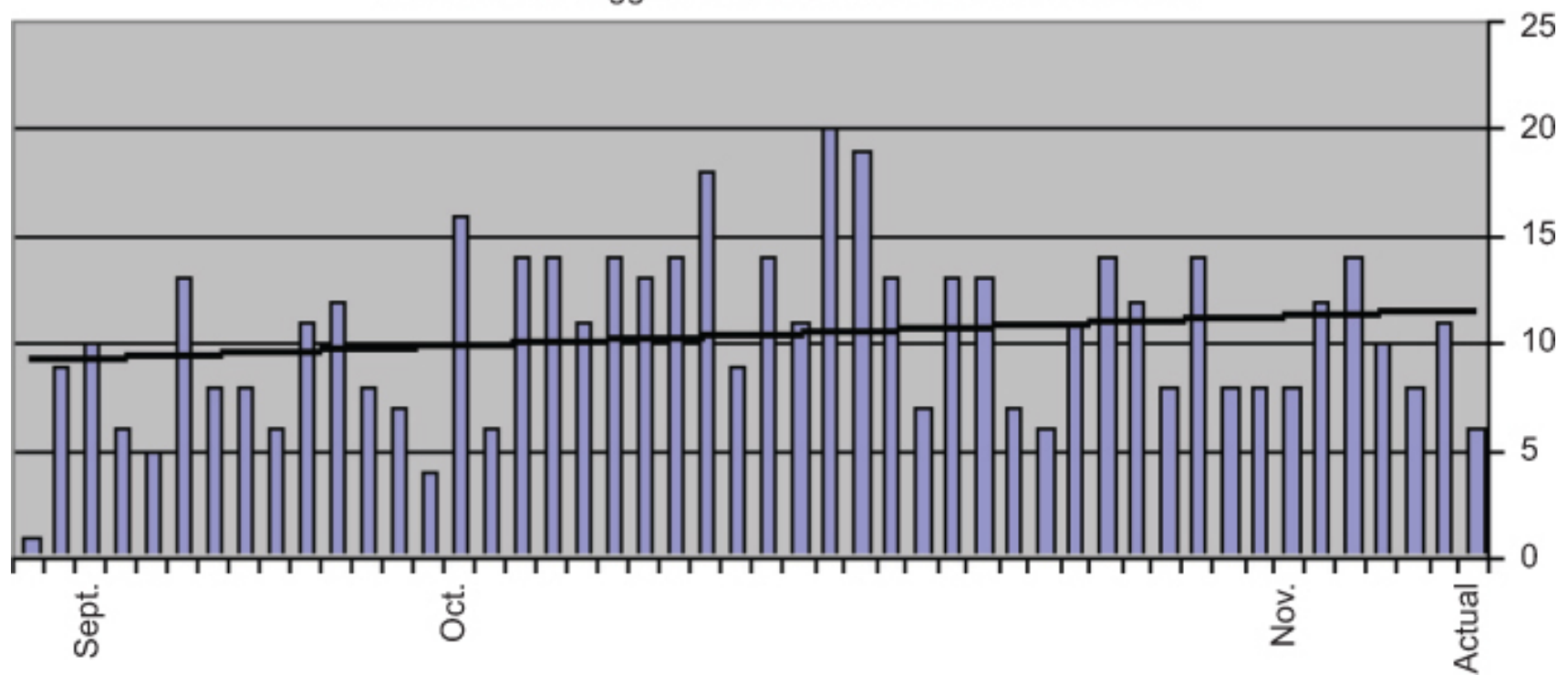

Figure 1

Daggett \% Trend in READ Ballot Questions

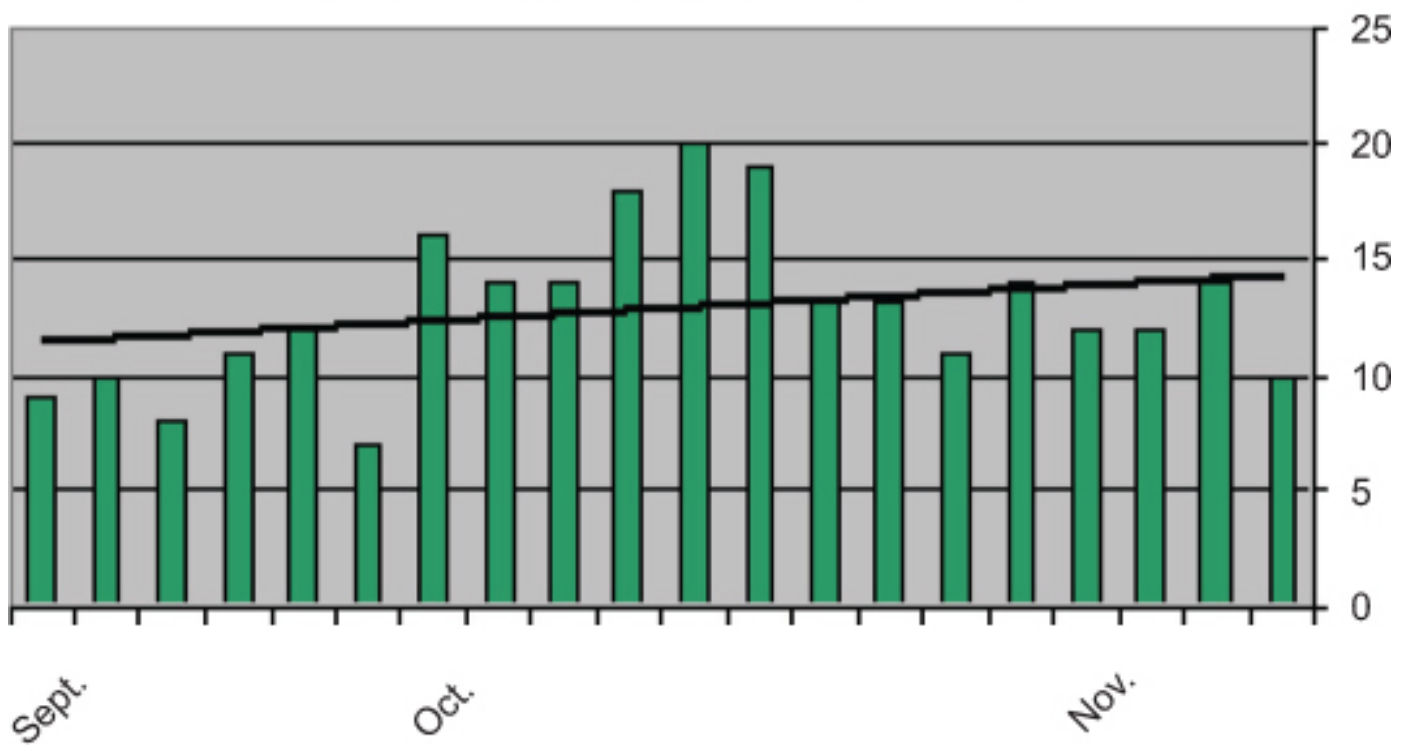

Figure 2

The following week, one independent poll reported Daggett at $4 \%$, another at

2 So said David Pringle of the New Jersey Environmental Federation to the Star-Ledger in "Chris Daggett, independent N.J. Gov candidate, qualifies for public funds.” July 07, 2009.

3 See FDU PublicMind, "Voters say N.J. on Wrong Track, Christie Leads Incumbent," July 1, 2009 found at http://publicmind.fdu.edu/30jun/ tab.html. 
$8 \%$. But the $8 \%$ was after reading his name; the same poll first read only the two major party candidates, and in that first heat, zero percent volunteered Daggett.

${ }^{4}$ This was a preview of what was to come, but was widely overlooked.

From there, Daggett's support appeared to increase steadily and by mid-October, a major media poll put Daggett's support at 14 percent, ${ }^{5}$ and a major university poll followed quickly that showed him at 20. ${ }^{6}$ Even Mark Blumenthal of pollster.com wondered aloud in the on-line National Journal "can Daggett pull a Ventura?" 7 But as Blumenthal noted, third party candidates have a steep climb, even when the going looks good.

No doubt some voters were looking for an alternative to the major party candidates: incumbent Corzine finished the race with an unfavorable rating of 52\%; challenger Christie did better, but not by much, with $45 \%$ of voters holding an unfavorable view of him. ${ }^{8}$ Some voters were clearly naming "independent Chris Daggett" as their choice simply as the alternative to two disliked options. But if this were the case, any candidate named along with the major party candidates would receive similar support.

Our view was that Daggett was attracting weak voters and weak partisans in the polls, who were drawn more to the label of "independent" which was read before or after his name, than by Chris Daggett himself, or any policy position he took. The question was how to test the proposition that Daggett's support was over estimated and over reported.

\section{RESEARCH DESIGN}

We tested this hypothesis by randomly assigning respondents to answer the ballot choice question in one of two ways. All respondents were asked the ballot question without Daggett, though allowing him to be volunteered. Then, we asked the ballot question again, randomly reading either Daggett as "the independent" or using a different candidate as "the independent." Our replacement for Daggett was Gary Steele, who was running as an "independent" for governor and would appear on the ballot throughout the state. An obscure tax attorney, his name was not known, nor was it suggestive

\footnotetext{
4 See: "Christie Up 12 In New Jersey, A Step Ahead On Boardwalk, Quinnipiac University Poll Finds" released July 14, 2009 at http://www.quinnipiac.edu/x1299.xml?ReleaseID=1348. Similarly, in an early August poll, Daggett got 0\% volunteered when unread and 7\% read: "Corzine inches up in New Jersey," released August 11, 2009, http://www.quinnipiac.edu/x1299.xml?ReleaseID=1362. Monmouth U. read Daggett's name but also offered "or someone else" and reported 4\% for Daggett in its release of July 16, 2009, http://www.monmouth.edu/ polling/admin/polls/MUP26_1.pdf. It consistently produced significantly more conservative results than those who did not offer "someone else" after Daggett.

5 The New York Times fielded their poll of 475 likely voters Oct. 9-14 and read “...or Christopher Daggett, the independent candidate.” See: http://graphics8.nytimes.com/packages/images/nytint/docs/the-new-york-times-new-jersey-poll/original.pdf.

6 Eagleton poll fielded Oct. 15-20 of 583 likely voters found at: http://eagletonpoll.rutgers.edu/polls/release_10-22-09.pdf and a Zogby poll appeared to support Daggett's high draw as well: http://www.zogby.com/soundbites/ReadClips.cfm?ID=19104.

7 Oct. 23, 2009 at http://www.nationaljournal.com/njonline/mp_20091023_1421.php. Blumenthal also commented earlier on his own site that "We know that support for independent and third party candidates often falls as election day approaches." See: http://www.pollster.com/blogs/ nj_daggett_the_key_wild_card.php.

8 FDU PublicMind, "New Jersey’s Blue Voters," Nov. 2, 2009, found at http://publicmind.fdu.edu/blue/final.pdf.
} 
of any particular ethnicity, nor did it seem to carry any particular associations. Thus, half of respondents at random were given a choice of the two major party candidates as well as "Chris Daggett, the independent" and half were given a choice of the two major party candidates and "Gary Steele, the independent." "

\section{RESULTS}

With his name unread and his support merely volunteered, Daggett's share was four percent in early October (with another four percent scattered among neither and others, and "don't know" garnering five percent). However, in the same poll, the same candidate included with the major party candidates as "Chris Daggett, the independent" garnered 17 percent of the vote (while "neither" and "other" went down to two percent and "don't know" was stable at six percent).

Meanwhile, Gary Steele, with his name unread, received no support at all. But thrown in the mix as "Gary Steele, the independent," his share was 12 percent. 10

In other words, the unknown-unfinanced-non-campaigning Steele suddenly polled nearly as well as the known-financed-hard-campaigning "independent, Chris Daggett" had been polling. It wasn't "Chris Daggett" the candidate who was attracting vote share. It was the tagline "independent" that some voters preferred. ${ }^{11}$ Indeed, the difference between polling 12 and 17 percent in the split sample was not even significant at $.05(\mathrm{z}=1.833)$.

On Election Day, Daggett's actual share was 5.8\%. Many stories suggested, as per usual, that the third party's support climbed, peaked, and declined. The explanation for the decline is the predictable one and, not coincidentally, the same one that his campaign offered: that because his supporters thought he could not win, they melted away. ${ }^{12}$ But the stronger evidence suggests that the trend line was erroneous, that no such support really existed at such high a level. Most voters in the polls that offered Daggett as a choice were not indicating support for him, but merely for "someone other than the two major party candidates." And while some voters were attracted to Daggett personally - a group approximately the size of the difference between Daggett's support and Steele's support in the experiment - there were far fewer of them than would be suggested by either the results reported by many pollsters, or the attention given to his candidacy.

\footnotetext{
9 See Appendix I for exact question wording.

10 And we noted with dismay that some journalists and bloggers began to report that a new third party challenger, Gary Steele, was getting 12 percent and spoiling the race!

11 Daggett's statewide name recognition was 50 percent while Steele's was, at best, 15\%. See Appendix II.

12 Mark Blumenthal summed up on Pollster.com: "And what happened to Daggett? Our final trend estimate had him at $10 \%$, but he received only $5.8 \%$ of the vote. Although it had been rising until mid-October, Daggett's support ultimately followed the traditional pattern. Many voters that had been intrigued by his candidacy ultimately concluded that their votes would be wasted and opted to support either Christie or Corzine.” (http://www.pollster.com/blogs/how_did_the_polls_do_in_2009.php).
} 
Table 1 Comparison of Independent Candidates Read and Unread in Split Sample.

$\begin{array}{lllllll}\begin{array}{l}\text { RDD, LV Sept. } \\ \text { 28-Oct. 5 }\end{array} & \text { Share } & \mathrm{N}= & \begin{array}{l}\text { Daggett over } \\ \text { Steele }\end{array} & \begin{array}{l}\text { Change from unread to } \\ \text { read }\end{array} & \begin{array}{l}\text { Neither/ } \\ \text { Other }\end{array} & \begin{array}{l}\text { Don't } \\ \text { know }\end{array} \\ \text { Daggett unread } & 4 \% & 667 & +4 & 13 & 4 \% & 5 \% \\ \text { Steele unread } & 0 \% & 667 & & 12 & 4 \% & 5 \% \\ \text { Daggett read } & 17 \% & 336 & +5 & 13 & 2 \% & 6 \% \\ \text { Steele read } & 12 \% & 331 & & 12 & 3 \% & 8 \%\end{array}$

\section{IMPLICATIONS}

Polling houses often make a judgment of whether to include a non-major party candidate in their ballot question. In doing so, they may consider whether the candidate is on the ballot everywhere, how much money the campaign has and is likely to raise, name recognition and favorable ratings, whether the candidate will be included in debates, or the candidate's own history of voter support. At the same time, dark horse candidates, knowing that a polling house can exercise the discretion of including non-major party candidates in a survey, will sometimes lobby to have their name included. Journalists can be complicit in the pressure to include third party candidates in the poll since their interest is in reporting a good horse race, and fair minded researchers are naturally concerned that not including a potentially significant challenger by reading his name will underestimate his support.

The fact that most houses are most times reluctant to add a third party candidate to their ballot question reflects not just their informed skepticism that the candidacy may go nowhere, but also is an acknowledgement that reading a minor candidate's name may erroneously increase his or her vote estimate in the survey, perhaps even creating its own feedback loop, with overestimates leading to more attention and more overestimates. The evidence here suggests that that reluctance is justified.

And what would have been the result had Daggett not been included as a read choice in any poll in the fall of 2009? The tempting conclusion for many commentators would have been that his exclusion from voter surveys caused his distant third place finish, precluding him from ever breaking into the race. The data suggest otherwise. Rather than a candidacy with a grand rise and fall, it was a candidacy that never broke out of the margins. It was the polling itself that created the illusion of competitiveness, a mere artifact of asking the question. 